\title{
Low voltage and fast speed all-polymeric optocouplers
}

\author{
Yan Yao, Hsiang-Yu Chen, Jinsong Huang, and Yang Yang ${ }^{\text {a) }}$ \\ Department of Materials Science and Engineering, University of California, Los Angeles, California 90095
}

(Received 14 November 2006; accepted 3 January 2007; published online 1 February 2007)

\begin{abstract}
An all-polymeric optocoupler has been demonstrated with a polymer light-emitting diode (PLED) as the light source (input unit) and a polymer/fullerene photodiode (PD) as the detector (output unit). The electroluminescence (EL) peak of the PLED is $560 \mathrm{~nm}$, and the entire EL spectrum is within the response range of the PD. The optocoupler can work at low driving voltages, $5 \mathrm{~V}$ on the PLED and $0 \mathrm{~V}$ on the PD. The output photocurrent increases linearly with input current, and the current density transfer ratio reaches $1.5 \%$. The frequency response of the optocoupler is at $500 \mathrm{kHz}$. With comparable performance to their inorganic counterparts, the all-polymeric optocouplers demonstrated here will bring the technology of organic photonic devices one step closer to commercialization. (C) 2007 American Institute of Physics. [DOI: 10.1063/1.2437683]
\end{abstract}

An optocoupler is a functional device that uses a short optical transmission path to transfer a signal between elements of a circuit, while keeping them electrically isolated. ${ }^{1,2}$ An electrical signal is converted to an optical signal and then back to an electrical signal. The optocouplers prevent electrical noise and voltage transients from interfering with other sections of a device and they are widely used in optoelectronics circuits. As an alternative to conventional inorganic counterparts, organic optoelectronics have attracted increasing attention due to their light weight, low cost, and potential for large area devices. ${ }^{3-7}$ The first polymer optocoupler was demonstrated by Yu et al. in $1994 .^{8}$ In the device, the input unit was a polymer light emitting diode (PLED) with an external quantum efficiency (EQE) of $1 \%$ photons/electron, and the output unit was a polymer photodiode (PD) with a quantum yield of approximately 35\% electrons/photon at $590 \mathrm{~nm}$ under $10 \mathrm{~V}$ reverse bias.

In recent years, especially after the concept of polymer and fullerene bulk heterojunction was demonstrated, ${ }^{9}$ the efficiency of photovoltaic devices has been significantly increased and photodetectors with EQEs higher than $76 \%$ have been successfully demonstrated. ${ }^{10}$ A significant improvement for PLED has been achieved by using phosphorescent materials $^{11,12}$ and interface engineering ${ }^{13,14}$ and internal quantum efficiency approaching unity was recently reported. ${ }^{15}$ However, no work has been carried out to improve the performance of optocouplers. Also little attention has been paid to the response time of optocouplers which is an important figure of merit to determine the highest signal frequency that can be transmitted. One recent report by Dong et al. showed an optocoupler with 6.5 s response time. ${ }^{16} \mathrm{Ob}-$ viously the response time is too long and needs to be reduced for practical applications. In this letter, we revisit polymer optocouplers by utilizing a donor-acceptor bulk heterojunction system as the PD, and demonstrate polymer optocouplers working at low driving voltage with high current transfer ratios and fast dynamic response.

The geometric structure and the corresponding circuit diagram of the polymer optocoupler are illustrated in Fig. 1. The input unit is a PLED with the structure of indium tin oxide (ITO) glass/PEDOT:PSS/PF/ $\mathrm{Cs}_{2} \mathrm{CO}_{3 /} \mathrm{Al}$, where

\footnotetext{
${ }^{a)}$ Electronic mail: yangy@ucla.edu
}

PEDOT:PSS is poly(ethylenedioxythiophene):polystyrene sulfonate and $\mathrm{PF}$ is polyfluorene consisting of $5 \mathrm{wt} \%$ poly (9,9-dioctylfluorene-co-benzothiadiazole) and $95 \mathrm{wt} \%$ poly(9,9-dioctylfluorene). PEDOT:PSS, PF, and $0.2 \%$ $\mathrm{Cs}_{2} \mathrm{CO}_{3}$ (in 2-ethoxyethanol) were spin coated onto the substrate layer by layer. Before coating $\mathrm{Cs}_{2} \mathrm{CO}_{3}$ layer, the device was heated at $60 \mathrm{C}$ for $30 \mathrm{~min} .80 \mathrm{~nm}$ thick $\mathrm{Al}$ was thermally deposited as the cathode after spin coating the $\mathrm{Cs}_{2} \mathrm{CO}_{3}$ layer. The output unit is a PD with the structure of ITO/PEDOT:PSS/P3HT:PCBM/Ca/Al, where P3HT is poly(3-hexylthiophene) and PCBM is $(6,6)$-phenyl- $\mathrm{C}_{61^{-}}$ butyric acid methyl ester. The active layer was spun cast from a blend solution of P3HT and PCBM (1:1 weight ratio, $\mathrm{P} 3 \mathrm{HT}$ concentration $=20 \mathrm{mg} / \mathrm{ml}$ ) at $1000 \mathrm{rpm}$ for $30 \mathrm{~s}$, then covered with a Petri dish and dried slowly (see Ref. 17 for details). A Ca/Al electrode with the thickness of 20/80 nm was deposited subsequently by thermal evaporation. Finally, the PLED and photodiode were aligned carefully and glued together by index matching epoxy. The active areas of PLED and photodiode are 12 and $2 \mathrm{~mm}^{2}$, respectively, and the choice of smaller PD size allows us to achieve faster response due to smaller capacitance. The entire device was wrapped in black tape to prevent interference from the environment.

The input unit of the optocoupler was characterized by a source-measure meter (Keithley 2400) and a calibrated silicon photodiode. The brightness was measured using a spectrophotometer (Photo Research PR650). Current-voltage $(I-V)$ and luminescence-voltage $(L-V)$ curves are plotted in Fig. 2(a). It is found that the device shows current turn-on voltage at $2.0 \mathrm{~V}$ and light turn-on voltage at $2.2 \mathrm{~V}$, corresponding to the injection of holes and electrons, respectively. The inset shows the electroluminescence (EL) intensity dependence on the input current, which is proportional for more than three orders. The PD was characterized under illumination $\left(100 \mathrm{~mW} / \mathrm{cm}^{2}\right)$ using a Thermo-Oriel solar simulator. The $I-V$ characteristic is shown in Fig. 2(b) with the short circuit current density of $10.0 \mathrm{~mA} / \mathrm{cm}^{2}$. In the inset of Fig. 2(b), short circuit current density is linearly proportional to light intensity for more than three orders. Figure 2(c) shows the EL spectrum of the PLED with a peak centered at $560 \mathrm{~nm}$ and EQE of the photodiode, which is around $60 \%$ from 400 to $650 \mathrm{~nm}$. By optimizing the materials selection 


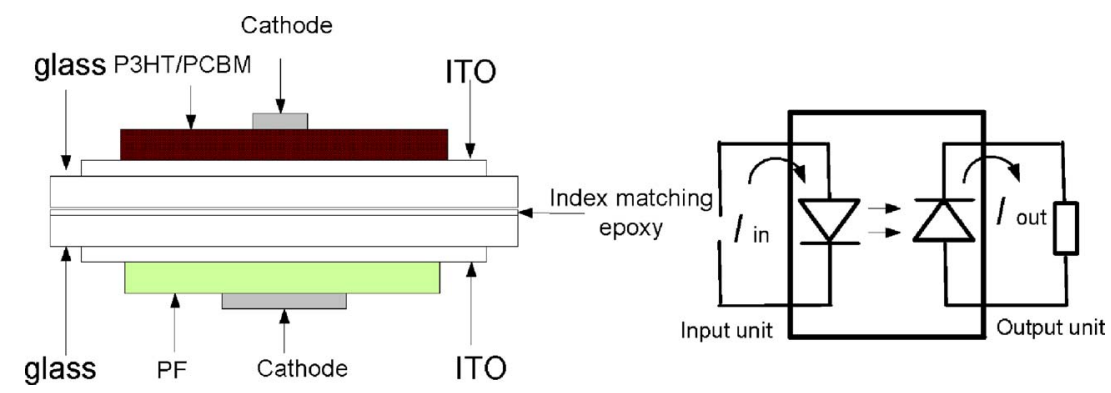

FIG. 1. (Color online) Schematic structure and corresponding circuit of the optocoupler.

process, all the photons emitted by the PLED contribute to the photocurrent of the PD, and the spectral overlap increases from an earlier value of $65 \%$ (Ref. 8 ) to $100 \%$.

Figure 3(a) plots the dependence of the output current of the PD $\left(I_{\text {out }}\right)$ measured using a semiconductor parameter analyzer (HP 4155C) on the input voltage to the PLED $\left(V_{\mathrm{in}}\right)$. When $V_{\text {in }}$ is less than the PLED turn-on voltage, $I_{\text {out }}$ is constant around $100 \mathrm{pA}$, which corresponds to the device dark current and is defined as $I_{\mathrm{OFF}}$. $I_{\text {out }}$ increases sharply when the PLED is turned on at $2.2 \mathrm{~V}$, and reaches $50 \mu \mathrm{A}$ at $8 \mathrm{~V}$. If $I_{\text {out }}$ is defined as $I_{\mathrm{ON}}$ when $V_{\text {in }}$ is $5 \mathrm{~V}$, the $I_{\mathrm{ON}} / I_{\mathrm{OFF}}$ value of the optocoupler is around $10^{5}$, which is sufficiently high to be used in digital circuits. The driving voltage $(5 \mathrm{~V})$ is also compatible with transistor-transistor logic (TTL) and complementary metal-oxide-semiconductor (CMOS) circuits.

In Ref. 8, the PD uses a pure polymer as an active layer and the photocurrent increases dramatically with reverse bias, hence the PD needs to be operated at $-10 \mathrm{~V}$ for high EQE. ${ }^{8}$ On the contrary, the photocurrent of the PD in this study [shown in Fig. 2(b)] shows only slight dependence on reverse bias. Our recent study on the self-organization induced ordering effect in the P3HT/PCBM blend films revealed that the $e-h$ pair dissociation efficiency was more than $80 \%$ under short circuit (SC) conditions. ${ }^{18}$ The high efficiency value and field independent behavior suggest that PD can be operated at very low applied bias, even under SC condition, which can further reduce the power consumption. The current transfer characteristic of the optocoupler between the input $\left(I_{\text {in }}\right)$ and output $\left(I_{\text {out }}\right)$ currents is shown in Fig. 3(b). $I_{\text {out }}$ is proportional to $I_{\text {in }}$ in the range of $10^{-6}-10^{-2} \mathrm{~A}$ as expected due to the linear response of PLED and PD, indicating that the optocoupler is also capable working in analog circuits. Current transfer ratio (CTR), defined as $I_{\text {out }} / I_{\text {in }}$, reaches $0.25 \%$, which is in the same range as that for regular inorganic optocouplers. ${ }^{1,2}$ We note that this value is achieved in the condition of no bias on the PD. Considering that only a part of the PLED area contributes to the photocurrent of PD, we divide $I_{\text {out }}$ by $2 \mathrm{~mm}^{2}$ and $I_{\text {in }}$ by $12 \mathrm{~mm}^{2}$ : the current density transfer ratio is $1.5 \%$. Improving the optical coupling efficiency between PLED and PD by optimizing device areas could be one effective way for further enhancing the CTR value.

In addition to high CTR value, the transient response is also important in the context of application of optocouplers in high-speed electronic circuits where their utility will ultimately be limited by the response time to high frequency modulation. A typical inorganic optocoupler with a single output phototransistor has a bandwidth of $200-300 \mathrm{KHz}{ }^{2}$ The transient behavior of EL from PLEDs has been extensively studied, because the pulsed excitation profiles provide direct information on the dynamic process leading to
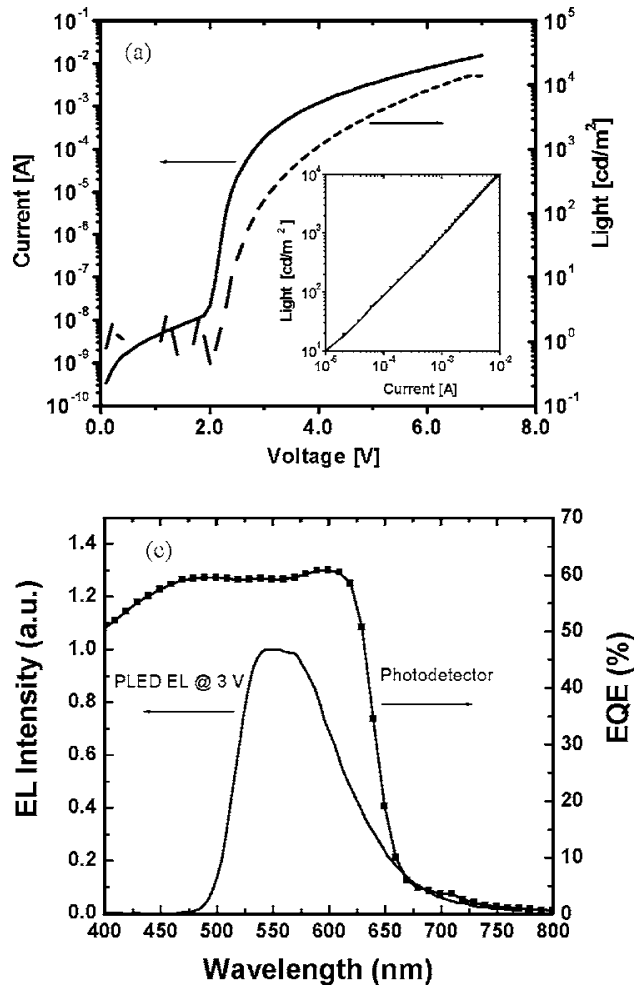

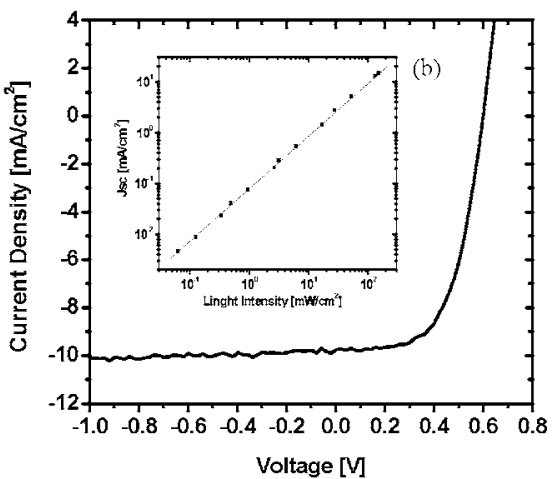

FIG. 2. (a) Current-luminance-voltage characteristic of PLED. Inset: luminance vs current. (b) $J$ - $V$ characteristic of the photodiode under AM1.5G $100 \mathrm{~mW} / \mathrm{cm}^{2}$ illumination. Inset: short-circuit current density $\left(J_{\mathrm{sc}}\right)$ dependence on the incident light intensity. (c) EL spectrum of PLED and $\mathrm{EQE}$ for the photodiode. 

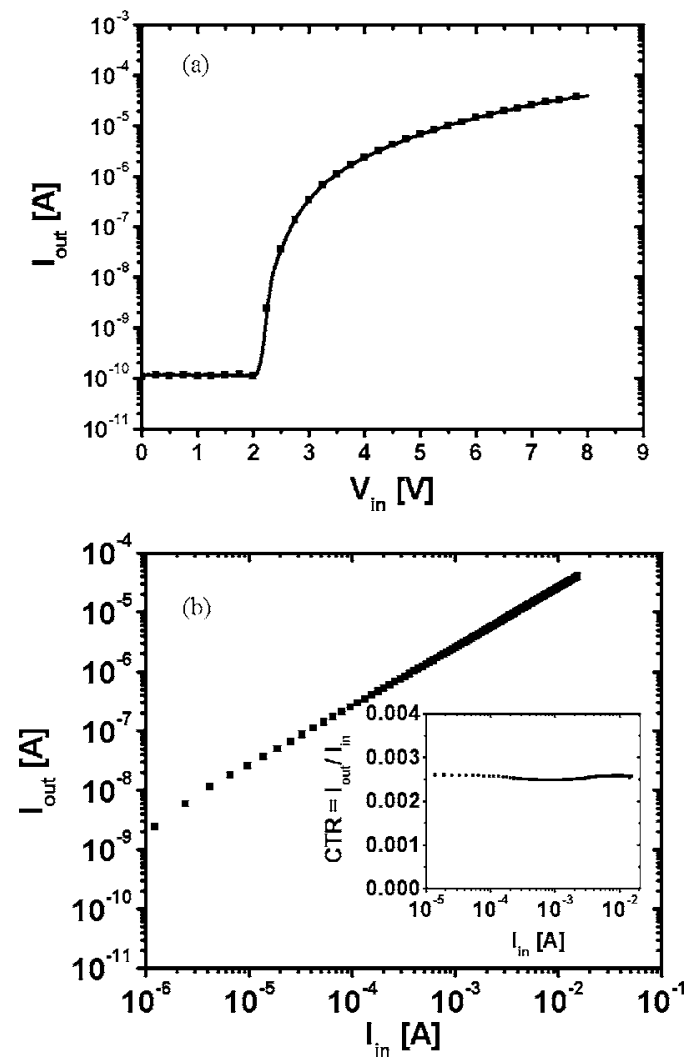

FIG. 3. (a) Current of the photodiode $\left(I_{\text {out }}\right)$ vs voltage of the PLED $\left(V_{\text {in }}\right)$ with photodiode under no bias condition. (b) Current transfer characteristics: current of the photodiode $\left(I_{\text {out }}\right)$ vs current of the PLED $\left(I_{\text {in }}\right)$. Inset: current transfer ratio vs $I_{\text {in }}$

EL. ${ }^{19-21}$ However, relatively few study has focused on the transient behavior of a PD with one report showing $0.8 \mu \mathrm{s}$ rise time for a polymer PD. ${ }^{22}$ Here we investigate the response time of our optocouplers with the test circuit shown in Fig. 4(a). A wave form generator (Waveteck 195) provides square wave forms of different frequencies that serve as input signal $\left(I_{\text {in }}\right)$. To measure the dynamic response of $I_{\text {out }}$, the photocurrent is amplified by a high bandwidth transimpedance amplifier (Femto DLPCA-200) and is displayed on an oscilloscope (Tektronix TDS 460A). Figure 4(b) shows that $I_{\text {out }}$ follows $I_{\text {in }}$ in the time domain nicely at a modulation frequency of $500 \mathrm{KHz}$. The rise and fall times of the photodiode are around $0.5 \mu \mathrm{s}$, which are seven orders faster than the previously reported value. ${ }^{14}$ This is by far one of the best results for polymer optocouplers and there is still room for improvement, such as selection of materials with higher charge carrier mobility and reduction of $R C$ time by decreasing device capacitance.

In summary, a polymer optocoupler with high CTR and fast rise time was demonstrated. The linear relationship between the output and input currents, together with high $I_{\mathrm{ON}} / I_{\mathrm{OFF}}$, qualifies the optocoupler for use in both analog and digital circuits. The optocoupler can be operated at low voltage $(<5 \mathrm{~V})$ and thus is compatible with both TTL and CMOS devices. Our results show that the polymer optocouplers have comparable performance to their inorganic
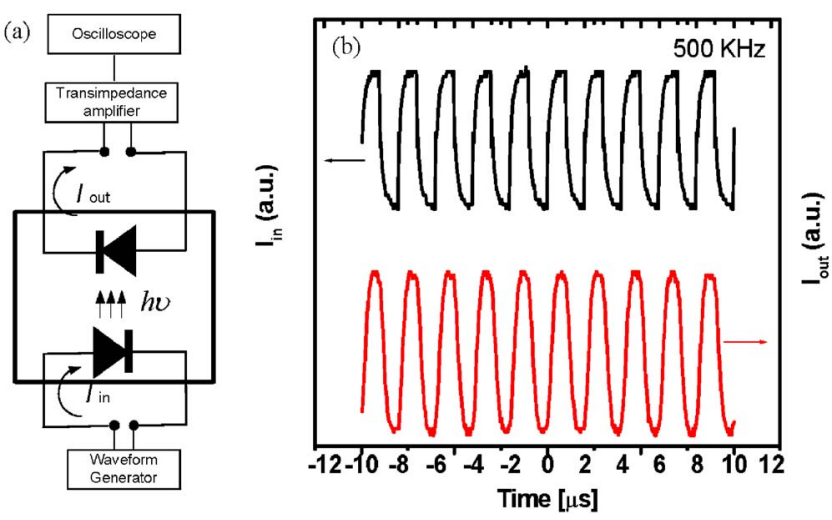

FIG. 4. (Color online) (a) Schematic diagram of the transient characteristics measurement. (b) The input and output currents vs time under $500 \mathrm{KHz}$ modulation.

counterparts and have bright future for commercial application.

The authors would like to thank Liping Ma for many useful discussions and Matthew Allen for proofreading this letter. This work was supported by the Solarmer Energy, Inc. (Grant No. 20061880) and the University of California Discovery matching grant (Grant No. GCP05-10208).

${ }^{1}$ U. Tietze, C. Schenk, and E. Schmid, Electronic Circuits: Design and Applications (Springer, Berlin, 1991), p. 99.

${ }^{2}$ S. Gage, D. Evans, M. Hodapp, and H. Sorenson, Optoelectronics Application Manual (McGraw-Hill, New York, 1977), Chap. 3, p. 14.

${ }^{3}$ R. H. Friend, R. W. Gymer, A. B. Holmes, J. H. Burroughes, R. N. Marks, C. Taliani, D. D. C. Bradley, D. A. Santos, J. L. Brédas, M. Lögdlund, and W. R. Salaneck, Nature (London) 397, 121 (1999).

${ }^{4}$ A. J. Heeger, Angew. Chem., Int. Ed. 40, 2591 2001; 33, 3514 (2000).

${ }^{5}$ F. Padinger, R. S. Rittberger, and N. S. Sariciftci, Adv. Funct. Mater. 13, 85 (2003).

${ }^{6}$ Sol. Energy Mater. Sol. Cells 83(2-3) (2004), special issue on the development of organic and polymer photovoltaics.

${ }^{7}$ MRS Bull. 30(1) (2005), special issue on organic-based photovoltaics.

${ }^{8}$ G. Yu, K. Pakbaz, and A. J. Heeger, J. Electron. Mater. 23, 925 (1994).

${ }^{9}$ X. H. Yang, D. C. Müller, D. Neher, and K. Meerholz, Adv. Mater. (Weinheim, Ger.) 18, 948 (2006).

${ }^{10}$ P. Schilinsky, C. Waldauf, and C. J. Brabec, Appl. Phys. Lett. 81, 3885 (2002).

${ }^{11}$ M. J. Yang and T. Tsutsui, Jpn. J. Appl. Phys., Part 2 39, L828 (2000).

${ }^{12}$ W. G. Zhu, Y. Q. Mo, M. Yuan, W. Yang, and Y. Cao, Appl. Phys. Lett. 80, 2045 (2002).

${ }^{13}$ X. H. Yang, D. Neher, D. Hertel, and T. K. Däubler, Adv. Mater. (Weinheim, Ger.) 16, 161 (2004).

${ }^{14}$ J. Huang, G. Li, E. Wu, Q. Xu, and Y. Yang, Adv. Mater. (Weinheim, Ger.) 18, 114 (2006).

${ }^{15}$ X. H. Yang, D. C. Müller, D. Neher, and K. Meerholz, Adv. Mater. (Weinheim, Ger.) 18, 948 (2006).

${ }^{16}$ G. Dong, Y. Hu, C. Jiang, L. Wang, and Y. Qiu, Appl. Phys. Lett. 88, 051110 (2006).

${ }^{17}$ G. Li, V. Shrotriya, J. S. Huang, Y. Yao, T. Moriarty, K. Emery, and Y. Yang, Nat. Mater. 4, 864 (2005).

${ }^{18}$ V. Shrotriya, Y. Yao, G. Li, and Y. Yang, Appl. Phys. Lett. 89, 063505 (2006).

${ }^{19}$ D. Braun, D. Moses, C. Zhang, and A. J. Heeger, Appl. Phys. Lett. 61, 3092 (1992)

${ }^{20}$ D. J. Pinner, R. H. Friend, and N. Tessler, J. Appl. Phys. 86, 5116 (1999).

${ }^{21}$ V. Savvateev, A. Yakimov, and D. Davidov, Adv. Mater. (Weinheim, Ger.) 11, 519 (1999).

${ }^{22}$ G. Yu, G. Srdanov, H. Wang, Y. Cao, and A. J. Heeger, Proc. SPIE 4108, 48 (2001). 